\title{
Services in a Development Round: Three Goals and Three Proposals
}

\author{
Aaditya Mattoo*
}

World Bank Policy Research Working Paper 3718, September 2005

The Policy Research Working Paper Series disseminates the findings of work in progress to encourage the exchange of ideas about development issues. An objective of the series is to get the findings out quickly, even if the presentations are less than fully polished. The papers carry the names of the authors and should be cited accordingly. The findings, interpretations, and conclusions expressed in this paper are entirely those of the authors. They do not necessarily represent the view of the World Bank, its Executive Directors, or the countries they represent. Policy Research Working Papers are available online at http://econ.worldbank.org.

*World Bank, Washington, D.C. 20433, USA. The paper has benefited greatly from the comments of Rudolf Adlung, Jens Arnold, Bernard Hoekman, Hamid Mamdouh, Julia Nielson and Richard Self. 


\begin{abstract}
The benefits of services trade reform are huge but services negotiations in the WTO are making little progress. A proximate cause is the current negotiating process, based on an inertial request-and-offer approach rather than a set of goals that would give direction and momentum to the negotiations. The paper suggests that WTO members should consider:

- locking in the current openness of cross-border trade for a wide range of services;

- eliminating barriers to foreign investment either immediately or in a phased manner where regulatory inadequacies need to be remedied; and

- allowing greater freedom of international movement at least for intra-corporate transferees and for service providers to fulfill specific services contracts.
\end{abstract}

A deeper problem is that WTO Members have sought to negotiate market access in services without adequately addressing concerns that GATS (General

Agreement on Trade in Services) commitments limit regulatory freedom unduly and unpredictably, that regulatory institutions in many countries are too weak to cope with liberalized markets, and that there is no provision for the regulatory cooperation that is necessary for successful liberalization, particularly of temporary labor mobility. Three types of actions are needed.

- At the current stage of its development, the GATS must focus primarily on disciplines for measures that discriminate against foreign services and providers, rather than on politically sensitive and legally complex rules for nondiscriminatory measures.

- A credible assistance mechanism must be established to help developing countries make the regulatory improvements needed for successful liberalization.

- Where necessary, WTO Members should make access commitments on labor mobility conditional on the fulfillment of specific conditions by source countries to screen services providers, accept and facilitate their return, and combat illegal migration. 
"Notwithstanding the fact that the number of offers has improved since my last report, it was widely acknowledged that the overall quality of initial and revised offers is unsatisfactory. Few, if any, new commercial opportunities would ensue for service suppliers. Most Members feel that the negotiations are not progressing as they should. It is clear that much more work will be necessary in order to bring the quality of the package to a level that would allow for a deal."

- Report by the Chairman, Alejandro Jara, to the Services Trade Negotiations Committee, July 2005. ${ }^{1}$

\section{OVERVIEW}

Much of the public discourse on the Doha Development Agenda has focused on trade in goods, particularly protectionist policies in agriculture. Negotiations on trade in services have received much less attention. The neglect matters. The potential benefits of services trade reform are huge but services negotiations in the WTO are making little progress.

One problem, of course, is that services negotiations are part of a stagnant whole. Progress in other areas, notably agriculture, is a necessary condition for progress in services. But it is not a sufficient condition. To produce a services outcome that supports broader development goals will require extraordinary intellectual, technical and political effort.

First of all, WTO Members need to end the current negotiating drift. Today Members negotiate by bilaterally submitting to each other requests (usually highly ambitious) which then bring forth a response of conditional offers (so far, mostly minimalist). This negotiating process has resulted in a low-level equilibrium trap where little is expected and less offered. To break free, Members need to identify a set of desirable and feasible goals to give both direction and momentum to the negotiations. These goals must be articulated not in arbitrary and opaque numerical terms, but in terms that resonate with the development and business community. The goals could initially be championed by a small group of Members, and articulated in model schedules to which a critical mass of Members would eventually subscribe. As discussed in more detail below, three broad goals seem both worthwhile and attainable:

- Locking-in the currently open regimes for cross-border trade in a wide range of services sectors.

- Eliminating barriers to foreign investment in sectors where there is no good reason to defer liberalization. And where the pre-conditions for successful liberalization can be fulfilled in a predictable time span, pre-committing to eliminate barriers at a future date.

\footnotetext{
${ }^{1}$ WTO Document TN/S/20.
} 
- Allowing greater freedom of temporary movement for individual service providers (mode 4) as intra-corporate transferees and to fulfill specific services contracts.

But to achieve these goals, WTO Members will also need to remedy the current negotiating tunnel vision. The focus on obtaining market-opening commitments has led to a relative neglect of the wider regulatory context. The neglect has made the market opening goal even more difficult to attain. In particular, Members need to respond to three substantive concerns:

- GATS commitments deprive regulators of the freedom to regulate and their full implications are impossible to predict;

- Regulatory institutions in a many countries are too weak to cope with liberalized markets; and

- There is no provision for the regulatory cooperation that is necessary for successful liberalization, particularly of labor mobility.

If the process of reciprocal market opening is to be revived, regulators must be reassured that regulatory freedom will be preserved, regulatory weaknesses remedied and regulatory cooperation facilitated. Three types of substantive actions can be taken to address these concerns:

- Make non-discrimination the focus of GATS commitments. So that we can reassure regulators that GATS commitments will deprive them only of the freedom to discriminate, and not limit their freedom in any other way. Where it is politically feasible and economically desirable, Members can assume further, clearly separate, obligations with regard to non-discriminatory measures and regulations.

- Establish a credible mechanism for regulatory assistance to support liberalization commitments by developing countries. So that we can reassure developing country policymakers that any regulatory inadequacies that could undermine the benefits of liberalization will be diagnosed and remedied before any market-opening commitments take effect. Rather than have, as at present, market-opening negotiations take their course without any link to international assistance for regulatory reform.

- Allow access commitments on labor mobility (mode 4) to be transparently and predictably conditional on the fulfillment of specific conditions by source countries. So that we can reassure immigration authorities that source countries will cooperate to screen services providers, accept and facilitate their return, and combat illegal migration. Rather than require, as at present, host countries alone to make binding commitments on an MFN basis, regardless of the conditions in or cooperative efforts made by source countries.

The first proposal is a response both to the opacity of GATS disciplines and to the tension today between widening and deepening the scope of these disciplines. The assumption is 
that a much wider range of commitments would be forthcoming if commitments were clearly understood to preclude only discrimination. And that the prevention of discrimination in a wide area is at this stage a more appropriate goal for the GATS than the imposition of far-reaching disciplines in a narrow area. The second and third proposals argue for the negotiations to be complemented by broader cooperation. The second proposal is based on the assumption that poorer developing countries would participate meaningfully in negotiations that offered an opportunity not merely to make binding commitments, but also to mobilize assistance for regulatory reform. The third is based on the assumption that migration authorities would engage constructively in negotiations that offered the opportunity not only to tie their hands, but also to secure assistance from source countries to deal with problems they cannot solve on their own.

It is possible that these assumptions are wrong and that there are other impediments to progress. But once the good reasons for holding back from making commitments have been identified and addressed, we can more fruitfully and with a clearer conscience focus on negotiating away the barriers to trade.

Section II spells out in slightly greater detail the three possible goals for the negotiations. Section III describes how the fulfillment of a set of substantive conditions may facilitate the attainment of these goals. The Annex describes possible refinements in the negotiating process.

\section{A Shared InTERest In Securing OPENNESS OF SERVICEs Trade}

Both industrial and developing countries could benefit greatly from reciprocal liberalization of the different modes of service delivery.

\section{I.1 Cross-Border trade: Dramatic growth and widening participation}

The shared interest in open services markets is vividly illustrated by the pattern of crossborder trade in business services. While industrial countries are still the largest exporters of such services (Figure 1), a number of developing countries are among the most dynamic (Figure 2). Since the mid-90s, the business services exports of 20 developing countries - including India, Israel, Brazil, Mauritius and Costa Rica- have grown by over 15 percent per annum.

Many countries, rich and poor, are reaping large efficiency gains from this enhanced international division of labor. And the development potential of cross-border trade in services is being felt in an ever-widening group of developing countries that are equipping themselves with the appropriate skills, infrastructure and institutions. 
Figure 1: Regional Distribution of Business Services Exports

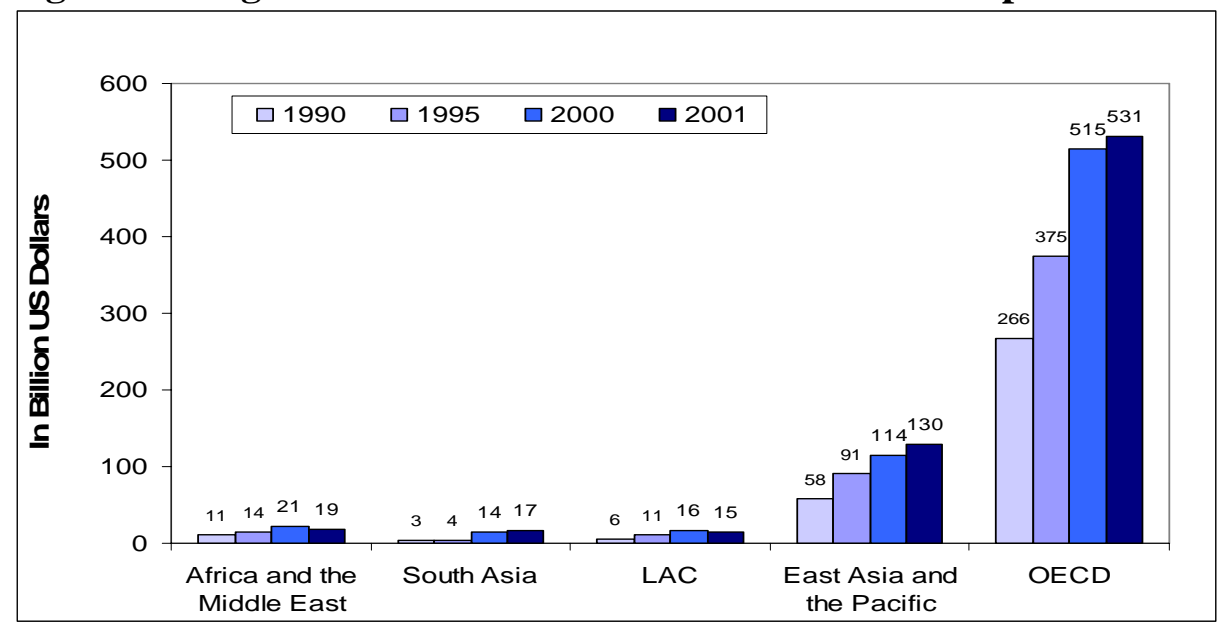

\section{Figure 2}

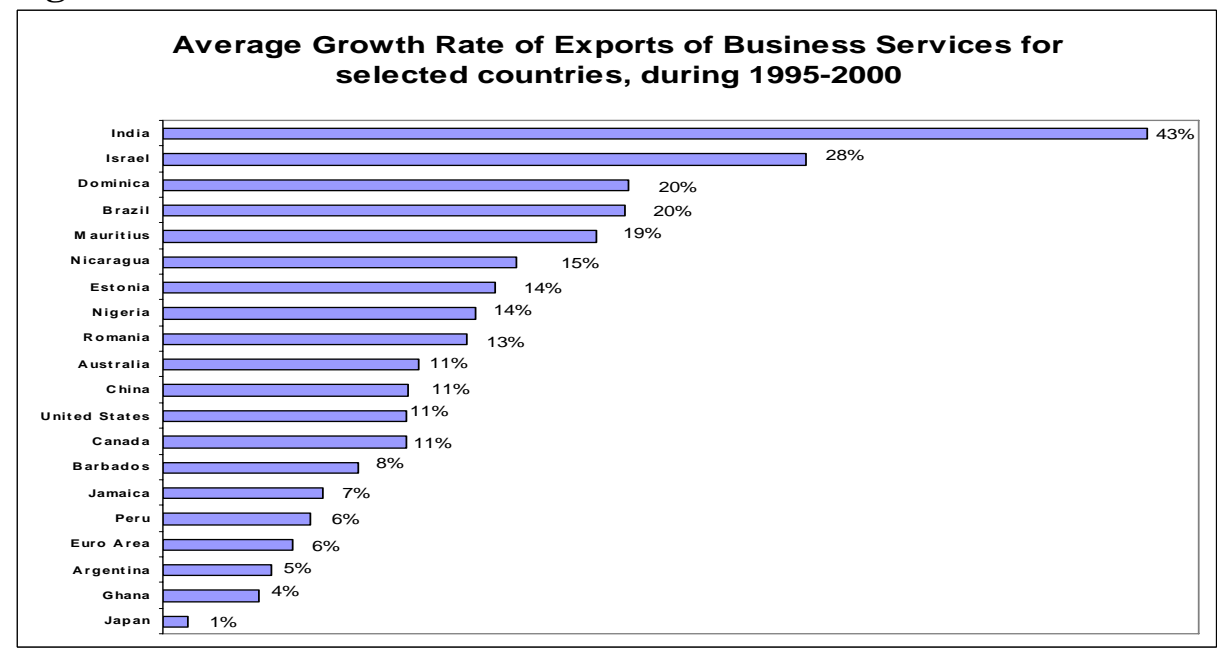

Source: IMF Balance of Payments Statistics; Note: -The “Business Services” category includes Total Services minus Transportation, Travel and Government Services. Alternatively, Business Services consist of: Communication, Construction, Insurance, Financial, Computer \& info, Other business, Personal, cultural and recreational services, as well as Royalties and License fees.

The resulting occupational shifts in importing countries and the implied adjustment costs have, however, raised the specter of protectionism. This specter may never materialize, because of the technical infeasibility of protection or the triumph of good sense. But it would still be wise to preempt protectionism, to ensure that any adjustment pressures are dealt with through desirable domestic assistance rather than inefficient barriers to trade. And if the GATS cannot secure existing openness, then what hope is there of eliminating entrenched restrictions? Hence:

- Goal 1: WTO Members would lock-in the current openness of cross-border trade for a wide range of services. Certain services, such as those that involve the mobility of capital, would be exempt. 


\section{I.2 The impetus to development from foreign investment in services}

Recent research supports the intuition that there are substantial gains from services reform, of which liberalization is an important element. One study finds that the gains from a cut in services sector protection by half would be five times larger than those from comparable goods trade liberalization (Robinson, et al, 1999). Another suggests that countries that successfully reformed their financial and telecommunications services sector grew, on average, about 1.0 percentage point faster than other countries (Mattoo et al. 2005). These findings are not surprising because current levels of protection in services are higher and liberalization would create spillover benefits from the inflow of capital and technology. The estimates of dynamic gains are also plausible, given the central role that the financial services play in the transformation of savings to investment, telecommunications in the diffusion of knowledge, transport in a country's ability to participate in global trade, education and health services in building up the stock of human capital, and business services in reducing transactions costs.

It would, however, be wrong to assume that these gains can be realized by a mechanical opening up of services markets. A flawed reform program can undermine the benefits of liberalization. For example, if privatization of state monopolies to private owners (sometimes foreigners) is conducted without creating conditions of competition, the result may be merely transfers of monopoly rents to private owners. Similarly, if increased entry into financial sectors is not accompanied by adequate prudential supervision, the result may be insider lending and poor investment decisions. Also, if policies to ensure universal service are not put in place, liberalization need not improve access to essential services for the poor. Managing reforms of services markets therefore require integrating trade opening with a careful combination of competition and regulation.

The challenge is to ensure that international commitments reflect good economic policy rather than the dictates of domestic political economy or international negotiating pressure. In particular, it is essential to distinguish between the areas where liberalization is prevented solely by the political power of vested interests - to which the WTO's reciprocal market opening is an antidote - and the areas where regulatory or other problems need to be remedied before the full benefits of liberalization can be reaped. Even in the latter case, if the time frame for reform could be predicted, a government would be in a position to decide whether to pre-commit in the WTO to future liberalization, in order to lend credibility to the reform program and/or to obtain a negotiating benefit.

Given the evidence of benefits conditional on appropriately designed reform programs, we have:

- Goal 2: WTO Members would eliminate barriers to foreign investment in sectors where there is no good reason to defer liberalization. And pre-commit to eliminating barriers where the necessary pre-conditions can be fulfilled in a predictable time span. 


\section{I.3 Significant global gains from temporary migration of service providers}

The most stringent barriers to service trade are to the mobility of individual providers or mode 4. Such temporary movement offers arguably the neatest solution to the problem of how some forms of international migration are best managed, enabling the realization of mutual gains from trade while averting to a large extent social and political costs in host countries and brain drain from poor countries. Recent research finds that if industrial countries were to allow temporary access to foreign service providers equal to just 3 per cent of their labor force, the global gains would be over $\$ 150$ billion - more than the gains from the complete liberalization of all trade in goods (Winters et al., 2003). These gains would be equally shared by the industrial and developing countries.

The challenge is to define a package that can liberate at least some forms of movement from the prohibitive political difficulties that have prevented any progress on mode 4 . First of all, in order to harness the coincidence of interest between industrial and developing countries, the package would include both intra-corporate movement and the movement of personnel independently of commercial presence. ${ }^{2}$ Secondly, in order to remain politically feasible, the proposed liberalizing commitments could be limited in three dimensions: they could apply only above specified skill thresholds; be for strictly temporary presence of a specified duration (say, less than one year); and, for independent movement, be only to fulfill services contracts and not to enter into employment. Countries would of course be free to make adopt more flexible and liberal regimes for other types of movement; for example, it may be possible to make greater progress on the movement of the unskilled through bilateral agreements to which the WTO should acquiesce. But the GATS negotiations would most fruitfully focus on the type of movement for which there seems to be an emerging international market, and for which multilateral negotiations can help eliminate explicit restrictions and create streamlined procedures.

Hence:

- Goal 3: WTO Members would allow greater freedom for the temporary presence of at least some categories of individuals, such as intra-corporate transferees and service providers to fulfill specific services contracts.

\footnotetext{
${ }^{2}$ While these two categories may seem traditionally to correspond to Northern and Southern interests, respectively, today the South has a growing interest in intra-corporate movement and the North in the independent movement of personnel.
} 


\section{ADDRESSING THE CONSTRAINTS}

In principle, the traditional WTO mechanism of reciprocal market-opening could help attain these three goals. In practice, the mechanism has simply not functioned in services because of inadequacies in the negotiating process, and the failure to win the consent and support of regulators. To revive reciprocity, the negotiating process must be reformed (see Annex for a proposal), but more importantly, regulators must be reassured - that regulatory freedom will be preserved, regulatory weaknesses remedied and regulatory cooperation facilitated. Each of these actions is relevant for all modes of service delivery but it is in some cases convenient to illustrate the significance of each with regard to a particular mode.

\section{Reassuring regulators that GATS commitments have clear implications and will not deprive them of the freedom to regulate effectively}

GATS rules and commitments raise two types of concerns for regulators: intrusiveness and inherent incomprehensibility. In certain respects, the constraints imposed by the GATS on policy-makers are predictable, and it is the desirability of the constraints that raises concerns. In certain other respects, GATS provisions are ambiguous with uncertain implications, and it is the risk of commitments that worries regulators. ${ }^{3}$

\section{Intrusiveness}

All international agreements between sovereign countries involve a trade-off between flexibility and security. In the GATS context, the challenge is to strike a balance between the cost of giving up some discretion to design services policies and the benefit of securing market access. At this stage of development of the Agreement, where many countries in most sectors have chosen to make no commitments at all, there is a serious choice to be made between widening and deepening commitments. The national treatment principle (Article XVII), i.e. agreeing not to discriminate de jure or de facto against foreign services and providers, seems to strike an appropriate and generally acceptable balance. On the one hand, the pursuit of most socially desirable objectives does not require treating foreigners less favorably; on the other hand, an assurance of non-discrimination is sufficient to overcome most impediments to market access. ${ }^{4}$

Going beyond national treatment, as the GATS does, to target also strictly nondiscriminatory measures does secure improved market access. But in some cases, the incremental benefit is unlikely to justify the political cost of limiting regulatory freedom

\footnotetext{
${ }^{3}$ In some cases, regulators themselves are the main defenders of a protectionist status quo and it will not be possible to win their support for greater openness. But the best way to address such regulatory recalcitrance is to address all legitimate concerns. The resistance that remains is fair game for the negotiations.

${ }^{4}$ There is inadequate appreciation of the powerful role the national treatment obligation will inevitably play in addressing a range of regulatory measures, such as licensing and qualification requirements, which discriminate in effect against foreign services or providers (Mattoo, 1997).
} 
with regard to strictly non-discriminatory measures. To see why, note that there are two key GATS rules that go beyond national treatment: first, specific commitments on market access (Article XVI) preclude also non-discriminatory quantitative measures; second, once a Member makes specific commitments, an additional layer of disciplines, particularly on domestic regulations kicks in (Article VI).

The potential overreach problem with the first rule was illustrated by the WTO Panel and Appellate Body ruling on the gambling dispute between the United States and Antigua and Barbuda. Even though the Appellate Body substantially reversed the Panel ruling, both agreed that the US prohibition of internet gambling was inconsistent with the specific commitments the US had made on market access. The US prohibition applied (at least in principle) equally to foreigners and US providers, but the inconsistency arose because specific commitments on market access preclude even non-discriminatory prohibitions. In this specific dispute, the Appellate Body found that most of the nondiscriminatory measures could be justified under the GATS exceptions provision (Article XIV). But the more general issue remains: a Member that has made full market access commitments is not free to impose certain strictly non-discriminatory measures, such as prohibitions, unless they can be justified under the exceptions provision.

The second rule, Article VI on domestic regulations, has few teeth today. But Members are in the process of negotiating new disciplines (mandated by Article VI:4) that are supposed to ensure that "qualification requirements and procedures, technical standards and licensing requirements do not constitute unnecessary barriers to trade in services" (emphasis added). Moreover, if the current structure is retained, such disciplines would kick-in the moment a Member makes a specific commitment in a sector. In the current environment, it seems unlikely that Members will agree on new disciplines that give a WTO Panel the power to make judgments of what is "necessary". Still unless their scope is drastically curtailed, these ongoing negotiations can have a chilling effect on the willingness to make commitments.

\section{Inherent incomprehensibility and unpredictability}

The three WTO Members with the largest resources of trade experts and negotiators have each been a defendant in the three services disputes that have come before the WTO. And each Member - the EU (in the bananas dispute), Canada (in the automotive parts dispute), US (in the gambling dispute) - claimed to have been surprised by the full implications of the GATS as spelt out in Panel rulings. Yet WTO Members have rushed into a new round of negotiations to secure more commitments from more Members without taking any significant step towards clarifying the scope and implications of GATS provisions. There is serious danger of an inequitable outcome: the less experienced will be induced to bind while the more experienced hold back. In previous negotiations, Gambia and Guyana were among those who committed to allow unrestricted cross-border trade in financial services and the required mobility of capital, but the United States and the European Union did not. 
The ambiguity of a number of other untested GATS provisions is common knowledge. Consider the central triad of provisions relating to market access (Article XVI), national treatment (Article XVII) and domestic regulations (Article VI). The market access and national treatment provisions overlap, with discriminatory quotas falling within the scope of each. In a wide variety of situations where commitments under the two provisions differ, it is impossible to tell with any certainty which measures are precluded. Members have made a greater effort to delineate the scope of the domestic regulation provision visà-vis the market access and national treatment provisions, but the line is blurred and the scope of current and potential rules is uncertain. The main point here is that the current structure is unnecessarily messy. A solution is to make national treatment the focus of commitments. ${ }^{5}$ If and where necessary, further layers of obligations could be created or assumed with regard to non-discriminatory measures.

If national regulators are to support making commitments, they need to be reassured that these commitments have predictable implications and strike the appropriate balance between market access and regulatory autonomy. Fortunately, the necessary changes can be accomplished without a change in the structure of the GATS.

- Proposal 1: Make national treatment the focus of GATS commitments. In terms of the current GATS architecture, a Member willing to make a liberalizing commitment in a sector would specify no limitations under Article XVII (i.e. enter "none"), while under Article XVI, the Member would retain the right to impose non-discriminatory prohibitions or quotas (i.e. enter "unbound for nondiscriminatory measures"). Furthermore, Members would agree that a necessitytype test would not at this stage be part of any new disciplines negotiated under Article VI. If some Members wished, they could in some areas assume further, clearly separate, obligations with regard to measures and regulations that do not discriminate in any way against foreign services or providers.

\section{Reassure regulators, especially in poor countries, that regulatory inadequacies which could undermine the benefits of liberalization will be diagnosed and remedied before they open their markets}

Today market access in services is negotiated at the WTO. Assistance for regulatory reform is provided by multilateral institutions and other agencies. There is no link between the two processes.

This disconnect persists even though it is clear that improved regulation - ranging from prudential regulation in financial services to pro-competitive regulation in a variety of network-based services - will be critical to realizing the benefits of services liberalization

${ }^{5}$ GATT/WTO jurisprudence reveals that the national treatment obligation does not lend itself to a straightforward interpretation (see e.g. Horn and Mavroidis, 2004). But the basic notion of nondiscrimination is certainly well-established and well-understood in international trade law. 
in many sectors. Policy intervention will also be necessary to ensure universal service because liberalization per se will not always deliver adequate access to the poor. Regulatory institutions can be costly and require sophisticated skills. For example, even a bare-bones telecommunications regulatory authority is likely to cost around \$2 million each year, or $5 \%$ per cent of government budget in a country like Dominica. The Doha Declaration contains innumerable references to technical assistance, but not one of these is binding.

It is desirable to establish a credible link between regulatory assistance and liberalization commitments. Added urgency is lent by negotiating deadlines - improved offers to liberalize were to be submitted by the end of May this year - but negotiating pressure alone is hardly likely to produce the best responses. In the Uruguay Round negotiations, most countries erred on the side of caution and made few commitments to genuine liberalization while some may have gone too far. As noted above, some of the poorest countries have made full commitments on cross-border trade in financial services while some of the richest and most sophisticated have not. Malaysia, Pakistan, the Philippines and others were persuaded to protect foreign incumbents while they offered new entrants inferior conditions of operation - leading to less rather than more contestable markets. The liberalization of maritime and air transport, the high costs of which are today bigger barriers to trade than tariffs, were not even seriously negotiated and exemptions from competition law continue because of the power of vested interests.

Development institutions like the World Bank have a stake in the outcome of the services negotiations, because GATS negotiations can be harnessed to deliver much-needed reform and also because unbridled mercantilism could produce outcomes that are antithetical to development. So there is a need to determine: Is there a good reason to defer liberalization, and/or not to make binding commitments? For example, weaknesses in existing mechanisms for prudential or pro-competitive regulation, alleviating adjustment costs, and ensuring universal access in liberalized markets may be good reasons to hold back. If so, what needs to be done to create the preconditions for successful market opening?

- Proposal 2: The international development community would establish a mechanism, funded by donors, to diagnose and remedy regulatory inadequacies for developing countries that are considering make liberalizing commitments. Recourse to the mechanism would be voluntary. ${ }^{6}$

If such a mechanism is to work, then there must be a demand for assistance, which will only emerge if there are fewer suspicions and greater appreciation of its value. On the one hand, countries must be confident that the mechanism would serve their needs and not be a Trojan horse whose sole purpose is to induce them to make market-opening commitments. The mechanism must therefore be established in consultation with the

\footnotetext{
${ }^{6}$ Such a mechanism could be part of a broader "aid for trade" initiative of the type called for in the United Nations Millennium Project (2004) and by the G8 at Gleneagles in 2005. See also Hoekman (2005) and Prowse (2005).
} 
relevant countries; with credible funding for both the diagnostics and remedial action; and it would be clearly understood that recourse to the mechanism would not create an obligation to make commitments. On the other hand, user countries must also see the usefulness of establishing a link between negotiations and assistance in order to foster desirable reform. ${ }^{7}$

\section{Reassure regulators that access commitments can be made conditional on cooperation by regulators in other countries.}

Facilitating regulatory cooperation could help deal with apprehensions about liberalization on all modes. For example, in financial services, confidence in cooperation by the home country regulator could lead to openness to both commercial presence and cross-border trade. We focus here on the presence of natural persons or mode 4 . Progress in these negotiations has become a precondition for more meaningful developing country participation in the process of reciprocal market opening. And it is proving extremely difficult for a number of countries to make any "concessions" in this area.

How can we make mode 4 a positive outcome rather than a millstone for the services negotiations? First of all, Members need to recognize that simply asserting that mode 4 is about trade in services and not about migration cannot dispel deep-rooted fears raised by the entry of foreign providers. These fears have to be acknowledged and addressed. One way forward may be to take a more cooperative and less antagonistic approach to mode 4, drawing upon the experience of a few relatively successful bilateral and regional agreements. ${ }^{8}$

The inclusion of labor mobility in the framework of a multilateral trade agreement implies that obligations are assumed by host countries alone, to provide market access on an MFN basis regardless of conditions in source countries. In contrast, the assumption of obligations by source countries also is a key element of regional trade agreements (e.g. NAFTA and APEC) that have facilitated mobility of the skilled, and bilateral labor agreements (e.g. between Spain and Ecuador, Canada and the Caribbean, Germany and Eastern Europe) that have to a limited extent improved access for the unskilled. Source country obligations include pre-movement screening and selection, accepting and facilitating return, and commitments to combat illegal migration. In effect, cooperation by the source can help address security concerns, ensure temporariness and prevent illegal labor flows in a way that the host is incapable of accomplishing alone - and constitute a service for which the host may be willing to pay by allowing increased access.

\footnotetext{
${ }^{7}$ In the past, many developing countries either did not engage at all in the negotiations, or succumbed to the bandwagon effect, as in the basic telecommunications negotiations, where many rushed forward to submit schedules of commitments at the last minute, and the only directly linked assistance they received (including from the World Bank) was in drafting their schedules.

${ }^{8}$ This section draws on joint work with Julia Nielson.
} 
Can these elements be incorporated in a multilateral agreement? One possibility is that host countries commit under the GATS to allow access to any source country that fulfills certain pre-specified conditions - along the lines of mutual recognition agreements in other areas. Even if these conditions were unilaterally specified and compliance determined unilaterally, it would still be a huge improvement over the arbitrariness and lack of transparency in existing visa schemes. Eventually, it would be desirable to negotiate these conditions (and even establish a mechanism to certify their fulfillment) multilaterally rather than in an unequal, non-transparent and potentially labor-diverting bilateral context.

In the current GATS framework, when a country makes a market access commitment, it is obliged to grant a fixed level of access every year in the future regardless of domestic economic conditions. In contrast, bilateral labor agreements allow host countries to vary the level of access depending on the state of the economy. One example is the bilateral agreement between Germany and certain Eastern European countries, under which the quota on temporary migrants increased (decreased) by $5 \%$ for every one percentage point decrease (increase) in the level of unemployment. It may be desirable to consider GATS commitments along these lines, which allow necessary flexibility albeit in a transparent, predictable and objectively verifiable manner, and would be a big improvement over the opaque economic needs tests that infest GATS schedules.

- Proposal 3: Immigration authorities in Member countries would be requested to define a set of conditions that source countries need to fulfill - in terms of screening services providers, accepting and facilitating their return, and making efforts to combat illegal migration - to be eligible for an allocation of temporary presence visas. These conditions could be the basis for a dialogue between immigration authorities in host and source countries. GATS commitments on mode 4 would be transparently and predictably conditional on source country cooperation and host country economic conditions.

\section{CONCLUSION}

There is considerable scope for the WTO to play its traditional role of facilitating reciprocal liberalization, not only by exploiting trade-offs across goods and services but also within services. But for the process to work, the negotiating process must be reformed and regulators must be reassured. These steps may help generate a virtuous cycle of mutually beneficial liberalization rather than a bitter round of grudging concessions.

To summarize the main proposals in this paper:

First, Members would adopt, or at least complement the current request-and-offer approach with, a collective approach to negotiations. Groups of Members would champion clearly specified goals and articulate them in model schedules (or model 
regulatory principles). By appropriate choice of sectors and level of commitments, agreement would be secured among a critical mass of Members.

Second, a critical mass of Members would lock-in the current openness of cross-border trade in a wide range of services, while retaining the right to impose any regulation or restriction that does not discriminate against foreigners.

Third, a critical mass of Members would eliminate barriers to foreign investment in sectors where there is no good reason to defer liberalization. And pre-commit to eliminating barriers where the necessary pre-conditions can be fulfilled in a predictable time span. To complement this effort, there would be a multilateral commitment to help poor countries establish regulatory mechanisms necessary for successful liberalization.

Finally, a critical mass of Members would allow greater freedom for the temporary presence of intra-corporate transferees and of service providers to fulfill specific services contracts. Commitments in this area could be transparently and predictably conditional on the unemployment rate in host countries and on source countries assuming obligations regarding certification, repatriation and illegal immigration. 


\section{Annex: Reforming the services negotiating process to further desirable goals}

Between identifying worthwhile goals and making them an integral part of the negotiations, falls the shadow. How can negotiations be informed by and lead towards desirable goals?

The current bilateral request-and-offer approach, adopted as the dominant negotiating method in the services negotiations, is leading nowhere. There is a strong case for adopting, or at least complementing the request-and-offer approach with, certain collective approaches to negotiations. First, in a world of unequal bargaining power, multilaterally agreed approaches that must be seen to be equitable and efficient are likely to produce a more desirable outcome than bilateral negotiations. Second, avoiding the need to barter commitments sector-by-sector, country-by-country can substantially reduce the transactions costs of negotiations. Third, formulae can help overcome the freerider problem that arises in negotiations conducted under an MFN-based system. ${ }^{9}$ Finally, the use of multilaterally applied formulae is perhaps the only credible way to grant credit to the unilateral liberalizers. In contrast, it is much more difficult to ensure compensation for the loss of negotiating coinage caused by unilateral liberalization in a bilateral request-and-offer negotiation.

In goods negotiations, collective approaches have typically taken the form of formulae cuts in tariffs. In services, quantitative assessments of offers or numerical targets would be an unhelpful distraction because even the best available methods of quantifying barriers to trade are hopelessly inadequate. ${ }^{10}$ At best, it would be possible to measure differences in the sectoral coverage of commitments, possibly weighted by some crude measure of the level of openness. ${ }^{11}$ To get agreement on any such target would be extremely difficult and consume valuable negotiating time and energy. Even if agreement were reached on a target, it may merely invite a spate of dubious entries along the lines of "economic needs tests" to create the illusion of coverage. Such a result would confirm the high level of cynicism about the GATS process.

A far more fruitful collective approach would be for groups of Members, akin to the "friends" groups that already exist, to champion clearly specified goals - possibly similar to those identified above. These goals could be embodied in model schedules (or model regulatory principles) along the lines of the Understanding on Financial Services, the Telecommunications Reference Paper and the Model Schedule for Maritime Transport. The building blocks of model schedules are relatively straightforward, and some have already been proposed for specific modes. ${ }^{12}$

\footnotetext{
${ }^{9}$ The problem arises in bilateral negotiations because each of the beneficiaries of a concession from a trading partner may be tempted to understate their willingness to pay for it, hoping that offers of reciprocal concessions from other Members will be sufficient to induce the concession.

${ }^{10}$ See Findlay and Warren (2003)

${ }^{11}$ See, for example, Hoekman (1996) and Mattoo (1999).

${ }^{12}$ See Chaudhuri et al. (2004) and Mattoo and Wunsch (2004).
} 
By an appropriate choice of sectors and levels of openness, it should be possible to strike a balance between collective commitment and individual flexibility, as well as between sound policy and negotiating imperatives. Different levels of ambition are possible. At the very least, this approach can provide a framework for negotiations. Or it could help establish a presumption in favour of a certain threshold level of commitments. Or it could represent a formula for liberalizing commitments, analogous to the "zero-for-zero" goods formulae, with the objective of securing acceptance by at least a critical mass of Members - defined as a group of Members each of whom would be willing to accept the commitments provided all others in the group do so. Hence, we have: 


\section{References}

Chaudhuri, S., A. Mattoo and R. Self (2004), Moving People to Deliver Services: How Can the WTO Help?, Journal of World Trade, vol. 38, 363-393.

Findlay, C. and T. Warren (eds) (2000), Impediments to Trade in Services: Measurement and Policy Implications, Routledge Publishing, London and New York, 1-17.

Hoekman, B. (1996), Assessing the General Agreement on Trade in Services, in The Uruguay Round and the Developing Countries, W. Martin and L. A. Winters (eds.), Cambridge: Cambridge University Press, 1996.

Hoekman, B. (2005), Expanding WTO Membership and Heterogeneous Interests, forthcoming in the World Trade Review.

Horn., H. and P. Mavroidis (2004), Still Hazy After All These Years: The Interpretation of National Treatment in GATT/WTO Case Law on Tax Discrimination, European Journal of Internal Law, 15.

Mattoo, A. (1997), National Treatment in the GATS: Corner-stone or Pandora's Box?, Journal of World Trade, vol. 31, no. 1, 107-135.

Mattoo, A. (2000), Financial services and the WTO: Liberalization Commitments of the Developing and Transition Economies, World Economy, vol. 23, no. 3, 351-386.

Mattoo, A., R. Rathindran and A. Subramanian (2005), Measuring Services Trade Liberalization and its Impact on Economic Growth: An Illustration, forthcoming in the Journal of Economic Integration.

Mattoo, A. and S. Wunsch (2004), Pre-Empting Protectionism in Services: The WTO and Outsourcing, Journal of International Economic Law, vol. 7, 765-800.

Prowse, S. (2005), Aid for trade: Increasing Support for Trade Adjustment and Integration - A Proposal, DFID, mimeo.

Robinson, S., Z. Wang and W. Martin (1999), "Capturing the Implications of Services Trade Liberalization,” Paper presented at the Second Annual Conference on Global Economic Analysis, GL Avernaes Conference Center, Ebberup, Denmark, June 20-22.

UN Millennium Project, Task Force on Trade (2004), Trade for Development, New York, United Nations.

Winters L A, T L Walmsley, Z K Wang, R Grynberg (2003), Liberalising Temporary Movement of Natural Persons: An Agenda for the Development Round, World Economy, 26(8): 1137-61. 